\title{
Fuel Reduction Effect of the Solar Cell and Diesel Engine Hybrid System with a Prediction Algorithm of Solar Power Generation "
}

\author{
Shin'ya OBARA** and Itaru TANNO** \\ **Tomakomai National College of Technology, \\ Nishikioka 443, Tomakomai, Hokkaido 0591275, Japan \\ E-mail: shinya@me.tomakomai-ct.ac.jp
}

\begin{abstract}
Green energy utilization technology is an effective means of reducing greenhouse gas emissions. In this paper, the production-of-electricity prediction algorithm (PAS) of the solar cell was developed. In PAS, a layered neural network is made to learn based on past weather data and the operation plan of the hybrid system (proposed system) of a solar cell and a diesel engine generator was examined using this prediction algorithm. In addition, system operation without a electricity-storage facility, and the system with the engine generator operating at $25 \%$ or less of battery residual quantity was investigated, and the fuel consumption of each system was measured. Numerical simulation showed that the fuel consumption of the proposed system was modest compared with other operating methods. However, there was a significant difference in the prediction error of the electricity production of the solar cell and the actual value, and the proposed system was shown to be not always superior to others. Moreover, although there are errors in the predicted and actual values using PAS, there is no significant influence in the operation plan of the proposed system in almost all cases. In the operation plan of the system with PAS, there was a case where the fuel consumption decreased by $15 \%$ compared with other systems.
\end{abstract}

Key words: Solar Power, Diesel Engine, Neural Network, Operation Planning, Renewable Energy

\section{Introduction}

Utilization of the expansion of green energy is an effective method to reduce the amount of greenhouse gas discharge. However, energy supplies using green energy tend to be unstable, hence interconnection with commercial power and operations to link to present generating equipment are required with the stabilization of the energy supply in mind. In recent years, there have been remarkable improvements in battery performance and the equipment cost has declined. Therefore, it is considered that the operation optimization method for green energy, including the storage of electricity, will henceforth become important. The objective of this study involves developing an algorithm (PAS) to predict the electricity production of a solar cell, and to optimize the operation of a diesel-power-plant hybrid system with the green energy of unstable output power. Moreover, the relation between the prediction error of the PAS and the energy cost of the proposed system is clarified. To date, there has been considerable research concerning the operation plan of a hybrid system, combining a solar cell and a diesel power plant ${ }^{(1-4)}$. These research reports show that a reduction in energy cost can be realized by both the electricity production of a 


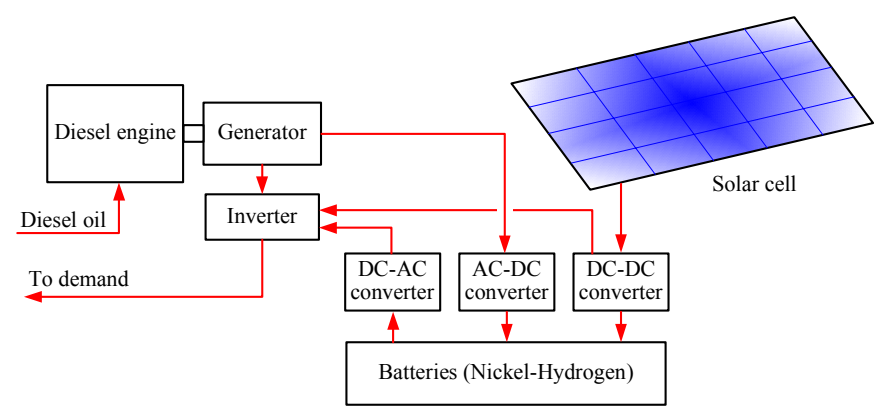

Fig. 1 System scheme

solar cell and the power load being predicted. If a large scale computer and considerable weather observation data are used, the solar radiation several hours later in arbitrary locations may be predictable. In this case, the electricity production of the solar cell can be correctly estimated. However, since using this method is costly in terms of communication and information, in this paper, a simpler algorithm for predicting the production-of-electricity of a solar cell is developed (PAS). In the PAS algorithm, a layered neural network $(\mathrm{NN})$ is made to learn using data on the amount of solar radiation and outside temperature for the past 14 years (NEDO, and the standard weather and the solar radiation database in 1990 to 2003 (METPV-3) ${ }^{(5)}$ ). As teaching data in this case, the electricity production of the polycrystalline-silicon-type solar cell, as calculated from the amount of slope-face solar radiation, is introduced. The weather data (the amount of solar radiation and outside air temperature) of each period, ranging from 24 hours earlier to the present, is given to the learned-NN, and the solar cell output power until several hours have been predicted and the operation of the engine and battery is planned based on this prediction result. Furthermore, the fuel consumption of an engine generator is compared with a system where the prediction operation plan has not been installed.

\section{System Configurations}

2.1 Solar cell and diesel engine hybrid system

Figure 1 is a schematic diagram of the solar cell and diesel engine hybrid system. The

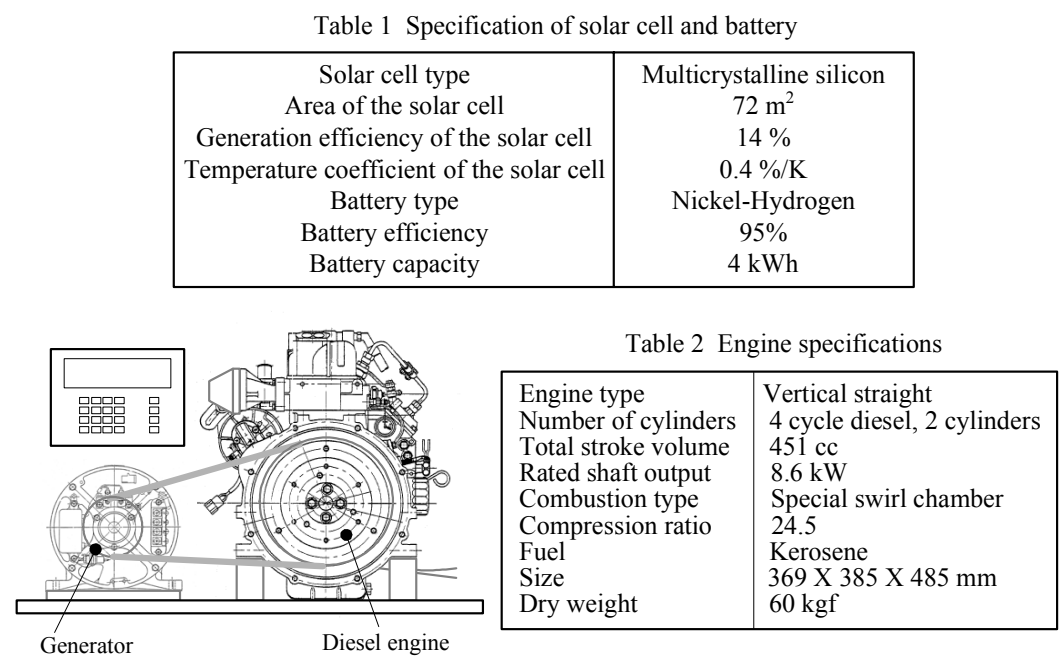

Fig. 2 Test diesel engine generator

Table 3 Generator specifications

\begin{tabular}{|l|l|}
\hline Generator type & Single-phase synchronized \\
Rated output & $5 \mathrm{kVA}$ \\
Rated voltage & $100 \mathrm{~V}$ \\
Rated electric current & $50 \mathrm{~A}$ \\
Frequency & $50 \mathrm{~Hz}$ \\
Number of revolution & $3000 \mathrm{rpm}$ \\
Size & $200 \times 221 \times 359 \mathrm{~mm}$ \\
& Automatic voltage regulator \\
\hline
\end{tabular}


system investigated in this paper is a specification capable of supplying power to an apartment house comprising three average households in Sapporo. This assumption is because the output power range of a general-purpose diesel engine is several kilowatts. The power output of the solar cell can be supplied to the demand side through a DC-DC converter and an inverter, or can be used to charge a battery. A nickel hydrogen type battery is used and the performance and specification were determined based on the reference ${ }^{(6)}$. The specifications of the solar cell and battery introduced into the analysis are shown in Table 1. Figure 2 is an outline view of the diesel engine, and shows the engine specification in Table 2. Moreover, the specification of the generator is shown in Table 3.

\subsection{Characteristics of the diesel engine generator}

Fig. 3 shows the relation of the fuel calorific power and the output characteristic of the diesel engine generator shown in Fig. 2. On the other hand, Fig. 4 shows the examination result of the output power and the generation efficiency ${ }^{(7,8)}$. The maximum power generation efficiency of the test engine generator is the case of $3 \mathrm{~kW}$ output. In analysis, the efficiency of this engine generator is calculated using the approximate expression shown in Fig. 4.

\subsection{Examination system}

In this paper, the following three systems (S-1, S-2, S-3) are examined, none of which involve power being supplied from the outside.

S-1 system: The engine generator is operated according to load fluctuation and no battery is installed. The surplus power of the solar cell can be sold off. In this system, because the engine is operated by a large area from a low to a high load, partial load operation with low efficiency occurs frequently.

S-2 system: When operating the engine, operate by the fixed load of maximum efficiency $(3 \mathrm{~kW}$ output power). However, the residual quantity of the battery is measured for every sampling period, and the operation or stop status of the engine is judged. Accordingly, if the battery capacity drops to $25 \%$ or less, the engine generator will be operated and the battery will be charged. The power of the solar cell exceeding the power load charges the battery.

S-3 system: The production-of-electricity prediction algorithm (PAS) of a solar cell is introduced, and the operation method of the system determined. Based on the predicted output characteristic of the solar cell, a plan is made concerning the operation or stop of the engine generator, and operation of the charge or discharge of the battery. When operating the engine, it is operated with a fixed load and at maximum efficiency ( $3 \mathrm{~kW}$ output power). When the power supplies from the battery to the demand side run short due to a prediction error, the engine generator is operated compulsorily.

\subsection{Battery capacity}

The cost of a nickel hydrogen type battery is about 100,000 yen/kWh $(940 \mathrm{US} \$ / \mathrm{kWh})^{(6)}$. The battery capacity introduced into the system in this paper shall be $4 \mathrm{kWh}$, which corresponds to about 170 minutes of an average household's power load $(0.47 \mathrm{~kW} \times 170$ minutes $\times 3$ households $=4 \mathrm{kWh}$ ). The optimal capacity of the solar cell and the battery must be discussed and determined for the dynamic operation plan.

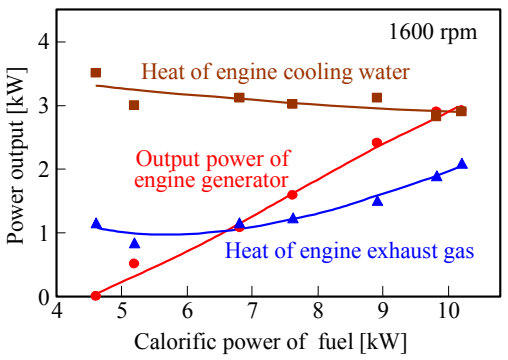

Fig. 3 Output of the diesel engine generator

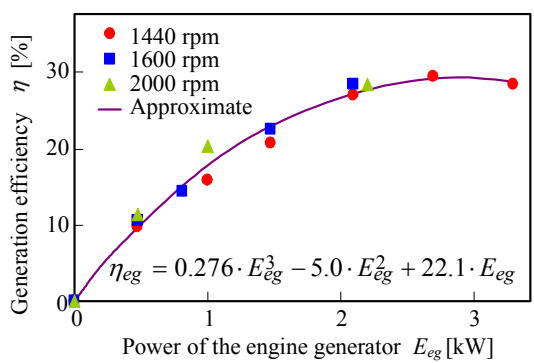

Fig. 4 Generator efficiency of the diesel engine 


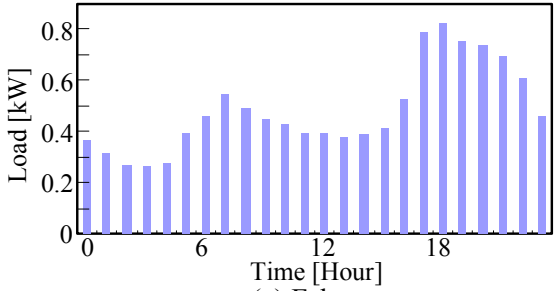

(a) February

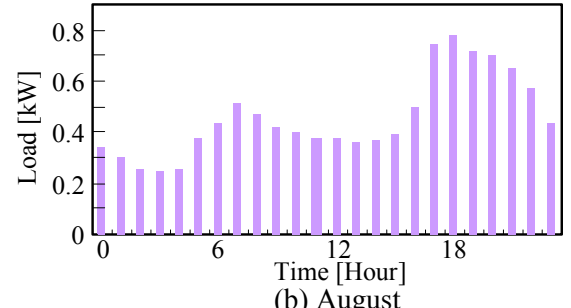

Fig. 5 Power load pattern of one household in Sapporo

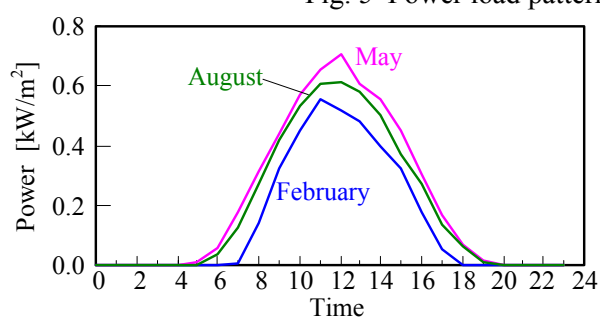

(a) Slope-face solar radiation

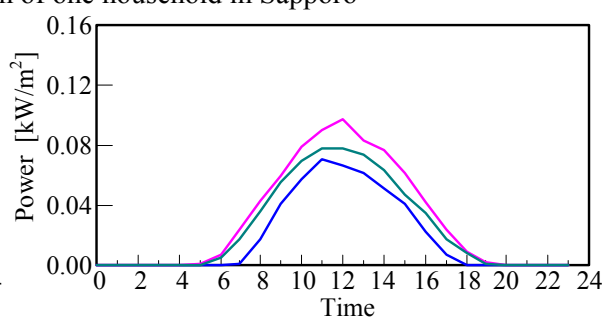

(b) The production of electricity

Fig. 6 Slope-face solar radiation and the production of electricity of a solar cell module in Sapporo

\subsection{Demand pattern}

In the analysis in this paper, the power load pattern in the general household in Sapporo shown in Fig. 5 is used ${ }^{(9)}$. As for the power load, the electricity consumption of a household appliance and an electric light is mainly included, and air conditioning load is not contained. For this reason, the difference in every month in the figure is small. The system of Fig. 1 with the operating method of S-1 to S-3 is introduced into 3 household apartment house with the load pattern shown in Fig. 5.

\section{Analysis Method}

\subsection{Amount of slope-face solar radiation}

In a flat plate type solar cell, direct solar and sky solar forms of radiation are used for power generation. The calculation method used to determine the intensity of solar radiation input into a solar power generation system is described below ${ }^{(10,11)}$. Global-solar-radiation intensity, direct solar radiation intensity, and horizontally sky solar radiation intensity are expressed with $I_{H}, I_{D}$, and $I_{S}$, respectively. If the intensities of direct solar and sky solar radiation are expressed with $H_{D}$ and $H_{S}$ among the solar radiation input into the acceptance surface, $H_{D}$ will be calculated by Eq. (1). $\theta$ on the right-hand side in Eq. (1) is an incident angle to the acceptance surface of the sunlight, and this value is calculated using Eq. (2).

$H_{D}=I_{D} \cdot \cos \theta$

$\sin \theta=\cos \varphi \cdot \sin \delta-\sin \varphi \cdot \cos \omega \cdot \cos \delta$

Here, $\varphi, \delta$, and $\omega$ show the latitude of a setting point, the solar celestial declination, and hour angle, respectively, while Equation (3) is a calculation formula for the sky solar radiation component $H_{S}$. The 1st term of the right-hand side of Eq. (3) is the air solar radiation component, the 2 nd term is the reflective solar radiation component, $\beta$ shows the angle of gradient of the acceptance surface by Eq. (4), and $\rho$ shows the reflection factor of the ground, respectively. In this paper, $H_{D}$ and $H_{S}$ are obtained from the standard weather and the solar radiation data base in the meteorology government office and AMEDAS (1990 to 2003) ${ }^{(5)}$, and the installation requirements of the solar cell by calculating Eqs. (1) to (4). Figure 6 shows the slope-face amount of solar radiation in the 
day to represent every month in Sapporo, installed on a 30 degree sloping roof facing southward.

$H_{S}=I_{S} \cdot \frac{1+\cos \beta}{2}+\rho \cdot I_{H} \cdot \frac{1-\cos \beta}{2}$

$\cot \beta=\cos \varphi \cdot \cot \omega+\sin \varphi \cdot \operatorname{cosec} \omega \cdot \tan \delta$

\subsection{Electricity production of solar cell}

A polycrystalline silicon solar module with $S_{S}$ is used in this paper. The average electricity production $P_{s, d p, t}$ of the solar module in days and months $d w$ and Time $t$ is calculated by Eq. (5). If the temperature $T_{c, d t, t}$ of the solar cell increases, the generation efficiency will fall. In this paper, as shown in Table 1 , the temperature coefficient $R_{T}$ is set to $0.4 \% / \mathrm{K}$, where $T_{o}$ is the reference temperature and $\eta_{s}$ the generation efficiency. Each value is made into $298 \mathrm{~K}$ and $14 \%$ in this paper. In analysis, the area of a solar cell shall be $72 \mathrm{~m}^{2}$, which is equivalent to about two houses of the general products installed in an individual house. The reason why the area of the solar cell is not equivalent to three houses is because the demand is satisfied. When the area of a solar cell set up expands, the battery capacity must also be increased. In consideration of the equipment cost incurred by a battery and solar cell, the specification was determined in this paper.

$$
P_{S, d w, t}=S_{S} \cdot \eta_{s} \cdot\left(H_{D, d w, t}+H_{S, d w, t}\right) \cdot\left\{1-\left(T_{c, d w, t}-T_{o}\right) \cdot\left(R_{T} / 100\right)\right\}
$$

\subsection{Prediction algorithm of the solar cell electricity production (PAS)}

In the S-3 system, the operation of the engine generator and battery is planned based on the prediction result of the electricity production of a solar cell and the system is operated according to this operation plan. In this paper, the electricity production of a solar cell is predicted via the following procedures using a layered neural network:

(1) Data of the slope-face solar radiation and outside air temperature

The data flow of the NN used in this paper is shown in Fig. 7. In the neural network learning process, the value of every time of slope-face solar radiation and the outside air temperature for the period 1990 to 2003 is read from the standard weather and solar radiation data base (METPV-3) and expressed with the data group shown in Eq. (6).

$$
\left(\bar{H}_{s, d w, t_{1}}, \bar{H}_{s, d w, t_{2}}, \ldots, \bar{H}_{s, d w, t_{24}}, \bar{T}_{o, d w, t_{1}}, \bar{T}_{o, d w, t_{2}}, \ldots, \bar{T}_{o, d w, t_{24}}\right)
$$

Where $\bar{H}_{s, d w, t}$ and $\bar{T}_{o, d w, t}$ are data indicating the slope-face solar radiation and outside air temperature in the days and months $d w$ and time $t$, which were obtained from METPV-3, respectively. Moreover, $i$ is 1 to 24 . When the data of Eq. (6) are input into $\mathrm{NN}$, the learning result based on the average for the past 14 years will be obtained. However, the repeatability of the meteorological data within a narrow period is very poor. Therefore, in this paper, the prediction calculation by the NN is analyzed over a one week period, so that it may be described below. The learning process of the NN in this study does not simply compare the past data of the prediction day. Firstly, the past data (solar radiation or outside air temperature) of the same week are added up and the measurement data of the solar radiation or the outside air temperature by the present is removed from this value. This result is allocated each time by the method described in the bottom, and predictive values 


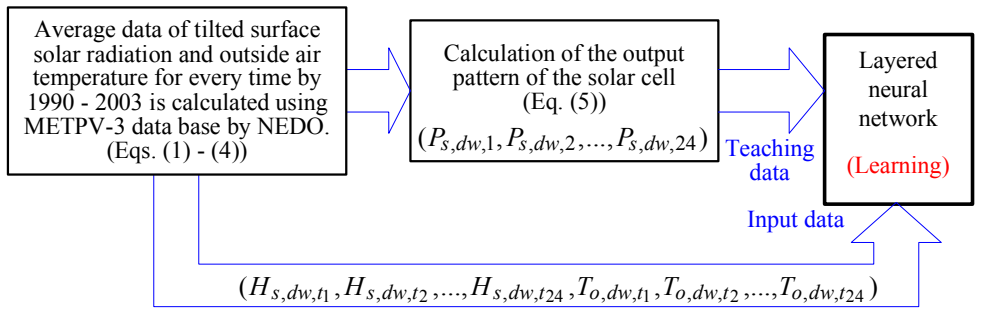

(a) Learning process

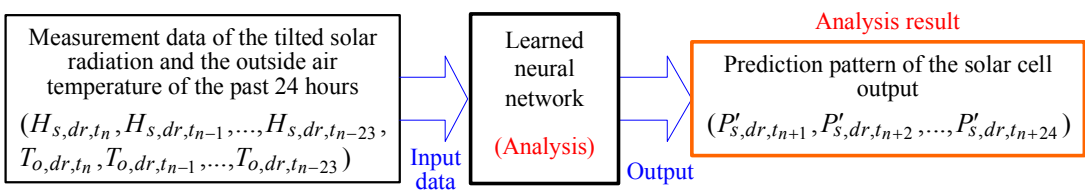

(b) Analysis process

Fig. 7 Prediction algorithm of solar power generation (PAS)

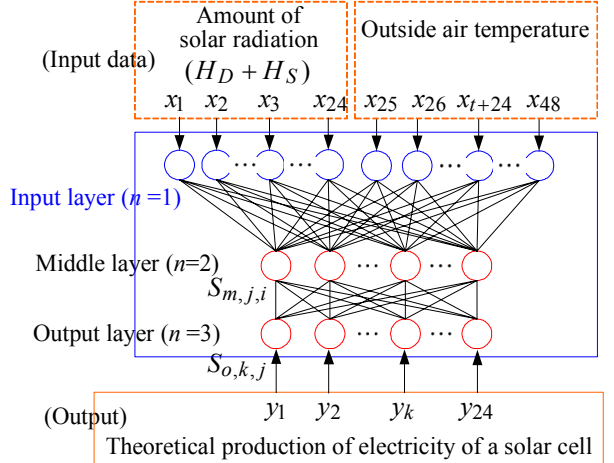

(a) Learning process

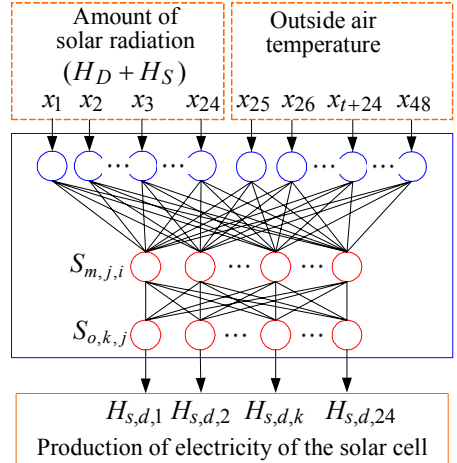

(b) Analysis process

Fig. 8 Layered neural network of the proposed system

concerning the amounts of slope-face solar radiation and outside air temperature are obtained.

(2) Learning calculation of the NN

The prediction day for the electricity production of a solar cell is expressed in $d w$ (order of the week). The data obtained from the data base are set to $\bar{H}_{s, d w, t}$. The daily mean value of the amount of slope-face solar radiation $\bar{H}_{d a y, d w}$ is calculated by Eq. (7) in this study, while the actual value before the prediction day (the 2nd term of the numerator) is subtracted from the sum of the amount of slope-face solar radiation of the same past week (the 1 st term of the numerator), and $\bar{H}_{d a y, d w}$ is obtained by dividing this value by the number of days $8-d w$ (where, $d w=1,2, \ldots, 7$ ). $\bar{H}_{d a y, d w}$ is multiplied by the rate $R_{H, d w, t}$ each time in Eq. (8), and the amount of slope-face solar radiation on the prediction day $d w$ and Time $t$ is determined by (Eq. (9)).

$$
\begin{aligned}
& \bar{H}_{d a y, d w}=\frac{\sum_{i=1}^{7} \sum_{t=1}^{24} \bar{H}_{s, i, t}-\sum_{j=1}^{d w-1} \sum_{t=1}^{24} H_{s, j, t}}{8-d w} \\
& R_{H, d w, t}=\left(\sum_{k=d w}^{7} \bar{H}_{s, k, t} /\left(\sum_{i=1}^{7} \sum_{t=1}^{24} \bar{H}_{s, i, t}-\sum_{j=1}^{d w-1} \sum_{t=1}^{24} H_{s, j, t}\right)\right) \\
& H_{s, d w, t}=R_{H, d w, t} \cdot \bar{H}_{d a y, d w}
\end{aligned}
$$

As $H_{S, d w, t}=\left(H_{D, d w, t}+H_{S, d w, t}\right)$, when these values and $T_{o, d w, t}$ are given to Eq. (5), the 
electricity production $P_{s, d w, t}$ in the solar module can be obtained. $P_{s, d w, t}$ is calculated each time, assuming $t=1$ to 24 in the days and months $d w$. The values of $P_{s, d w, t}$ are assigned to the $\mathrm{NN}$ as teaching data, while $T_{o, d w, t}$ is also obtained from the same calculation as $H_{s, d w, t}$.

(3) Prediction calculation by NN

The data flow in the analyzing process of the $\mathrm{NN}$ is shown in Fig. 7 (b). Present days-and-months and time are expressed with $d r$ and $t_{n}$, respectively and the electricity production of the solar cell from the present time $t_{n}$ to 24-hours after $\left(t_{n+24}\right)$ is predicted. The meteorology measurement data (actual value of the slope-face solar radiation and outside air temperature) of 24 hours previously is input into a learned neural network. Consequently, as shown in Fig. 7 (b), the production-of-electricity pattern

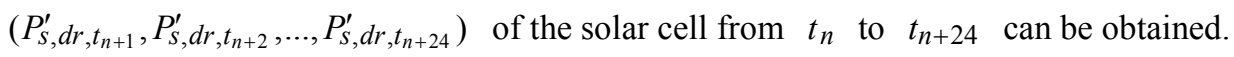

\section{(4) Structure of NN}

Figure 8 shows the structure of layered NN used by PAS. Figure 8 (a) shows the learning process and Fig. 8 (b) shows the analyzing process. The number of the layer of the NN is 3 , and the meteorological data and outside-air-temperature data (actual value) for each time are input into the input layer. During the learning process, teaching data are input into the 3rd layer (output layer), and the weight of each neuron, which connects the intermediate layer and each class, is set up. During the analyzing process, the electricity production of the solar cell for each sampling time is output from the output layer of the learned neural network.

\section{Analysis Result}

4.1 Electricity production of the solar cell, and power balance

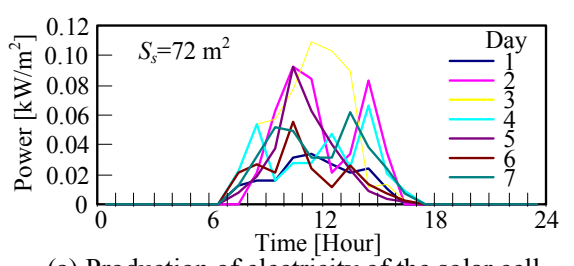

(a) Production of electricity of the solar cell

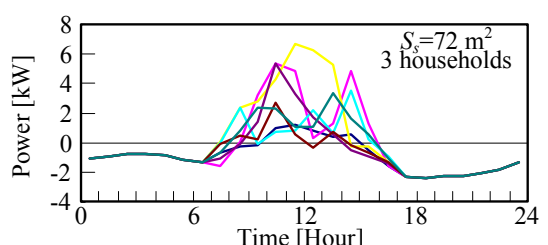

(b) Balance of the power (subtraction of solar power and power load) ver balance in February

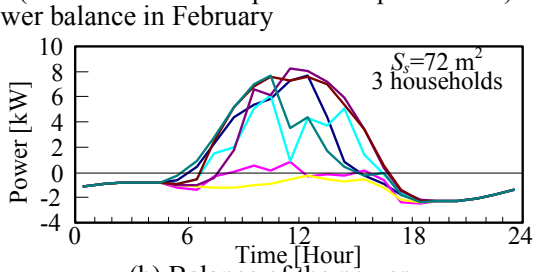

(b) Balance of the power

(subtraction of solar power and power load) Fig. 10 Solar power and power balance in August

(a) Production of electricity of the solar cell

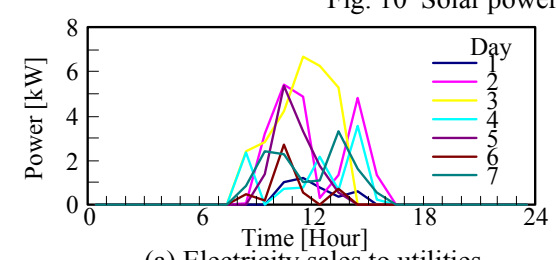

(a) Electricity sales to utilities

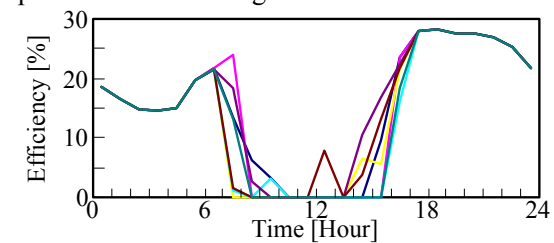

(b) Engine generation efficiency

Fig. 11 Operation result of S-1 system in February

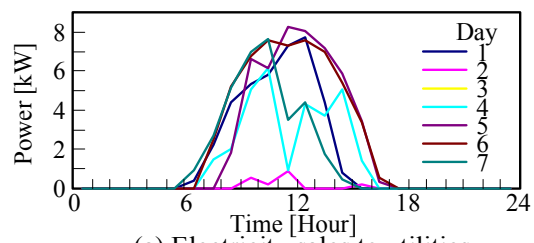

(a) Electricity sales to utilities

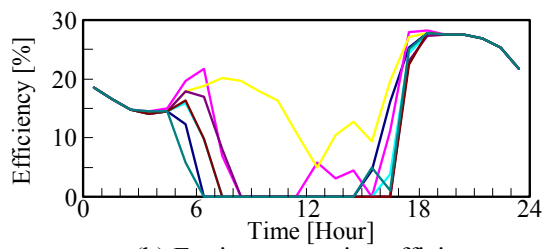

(b) Engine generation efficiency

Fig. 12 Operation result of S-1 system in August 


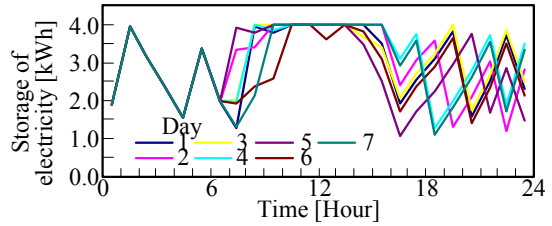

(a) February

Fig. 13 Operation result of the battery (S-2)

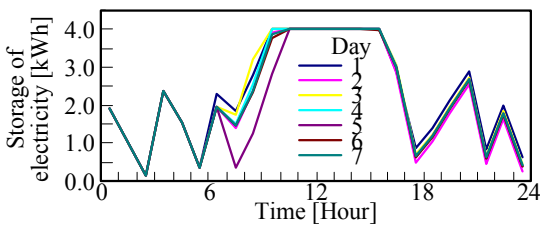

(a) February

Fig. 14 Operation result of the battery (S-3)

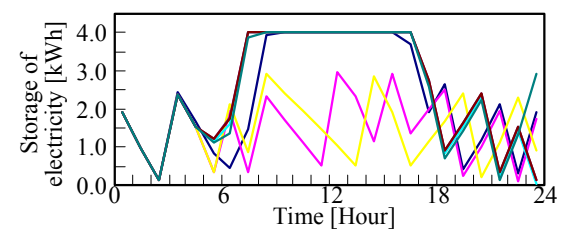

(b) August

Figures 9 and 10 show the electricity production of the solar cell and power balances (power load is subtracted from the electricity production of the solar cell) from the 1st to 7th for every month. Except for August 2 and 3, the majority of the daytime power load can be supplied with the power of the solar cell. However, around 7:00 and around 18:00, where there is significant power demand, there is insufficiency in the electricity production of the solar cell.

\subsection{Operation result of the S-1 System}

Figures 11 and 12 show the operation result of the S-1 system, the amount of electricity sales to utilities, and the generation efficiency of the engine generator. No battery is used in the S-1 system. During the period when the electricity production of the solar cell cannot meet the demand, the engine generator operates. Due to the particularly high power demand during every morning and evening period, in addition to the power of the solar cell, the operating load of the engine generator also increases. Consequently, as shown in Figs. 11 (b) and 12 (b), partial load operation with low efficiency occurs frequently. The average efficiency for each February day of the engine generator is $14 \%$ to $16 \%$, and will be $12 \%$ to $19 \%$ in August. There is an extreme lack of solar radiation on August 2 and 3 compared with other days in the same week, explaining the wide efficiency range of the engine generator in August. As shown in Fig. 4, the peak generation efficiency of the engine generator is about $30 \%$. In the $\mathrm{S}-1$ system, however, high efficiency cannot be maintained. When consideration is made of electricity sales to utilities, the economic efficiency of the S-1 system is good.

\subsection{Battery operation plan}

Figures 13 and 14 show the result of the operation analysis of the battery for the S-2 and S-3 systems. In the battery capacity ( $4 \mathrm{kWh}$ ) set up in this paper, none of the surplus power of the daytime solar cell can be stored as electricity. Except for August 2 and 3 in Fig. 14 (b), when Figs. 13 and 14 are compared, the frequency of battery charges and discharges of the battery occurs more in the S-2 systems. The extreme lack of solar radiation on August 2 and 3 , means the cycle of slight charge and discharge is repeated with the battery. In the S-2 system, when the battery charge amount declines to $25 \%$ or less, it will charge with the engine generator. On the other hand, operation of the charge and discharge of the battery can be planned within the S-3 system, meaning here that the frequency of charging by the engine generator can be reduced as much as possible. Consequently, the battery charge-and-discharge loss of the S-3 system and the fuel consumption of the engine generator can be reduced compared with the S-2 system.

In Figs. 13 and 14, power input exceeding battery capacity occurs in daytime, due to the considerable electricity production of the solar cell and overall system operation will be influenced when the area of a solar cell is changed. Concerning optimization of the area of a solar cell, this is a vital topic and separately reported upon. 

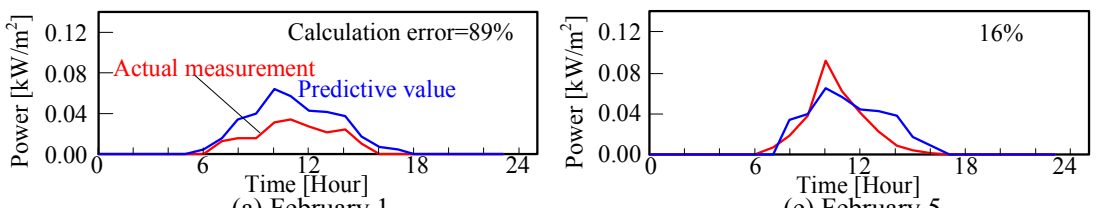

(a) February

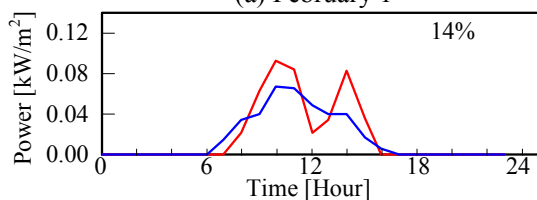

(b) February 2

(e) February 5

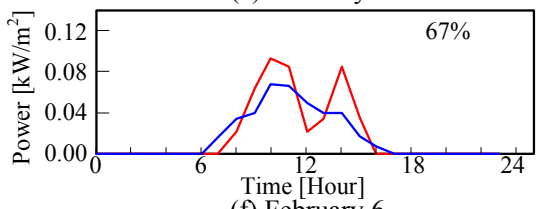

Time [Hour]
(f) February 6

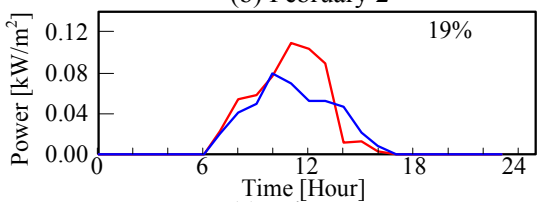

(c) February 3

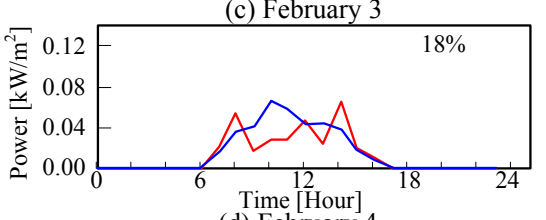

(d) February 4

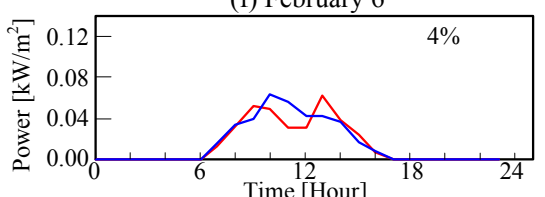

(g) February 7

Fig. 15 Predictive value of the production of electricity of the solar cell in February 1 to 7
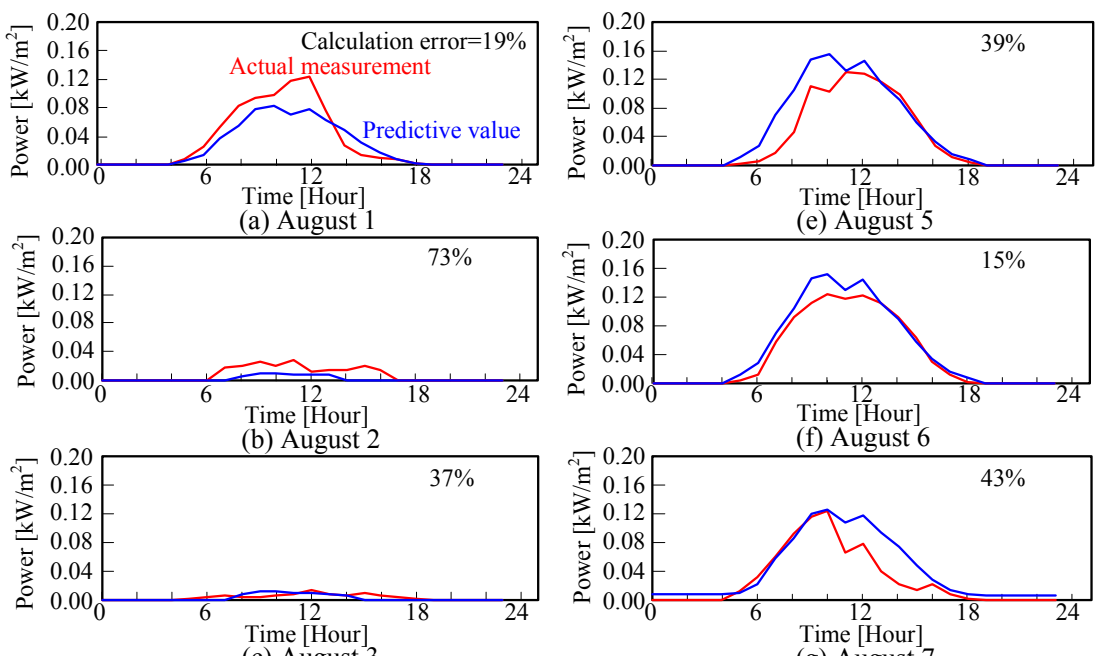

(c) August 3

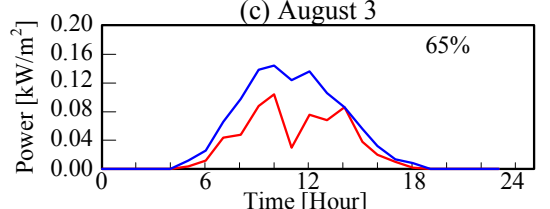

Time [Hour]
(d) August 4

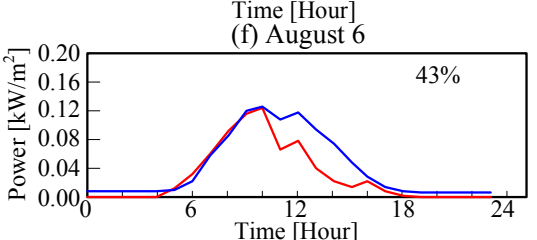

(g) August 7

Fig. 16 Predictive value of the production of electricity of the solar cell in August 1 to 7

\subsection{Result of the power generation prediction of solar cell}

Figures 15 and 16 shows the result of the production-of-electricity predictive value of the solar cell and the actual value for each day in February and August. The addition error of the solar radiation for one day is described in each figure. As shown in Figs. 16 (b) and 16 (c), the predictive value of the solar radiation on August 2 and 3, when an extreme lack of solar radiation was recorded, shows few characteristics. Figure 17 shows the difference in the predictive value between the amount of solar radiation and the actual value for each day and every month. The error for the 1 st week in February ranged from $4 \%$ to $89 \%$, and between $15 \%$ and $73 \%$ during the 1 st week in August.

The magnitude of the error of the predictive value and the actual value was investigated, namely in terms of its impact on the operation plan of the S-3 system. Accordingly, the 
difference in the prediction electricity production of the solar cell and the actual electricity production clarifies details of how this influence affects the fuel consumption of the engine generator. In the following, the analysis result of the operation plan of the engine generator in the S-3 system is described.

\subsection{Operation result of the engine generator}

Figures 18 and 19 show the operation result of the engine generator of the S-2 and S-3 systems in February and August, respectively, with the operation of each system planned for every sampling time. In the S-2 system, if the battery residual quantity falls to $25 \%$ or less, the engine generator will be operated. In the S-3 system meanwhile, based on the predicted electricity production of the solar cell, the operation of the engine generator is planned so that the power balance for every sampling time need not become negative. However, when there is a considerable operation prediction error, the battery power supply may be insufficient, in which case, the engine generator is operated immediately.

Compared with the engine operation hours of the S-2 system, the time for which the S-3

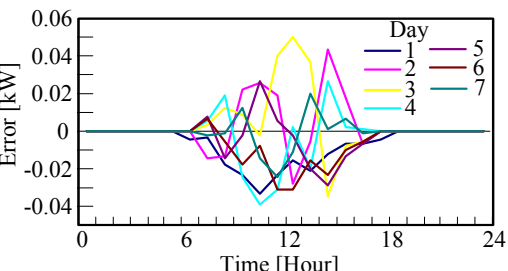

(a) February 1 to 7

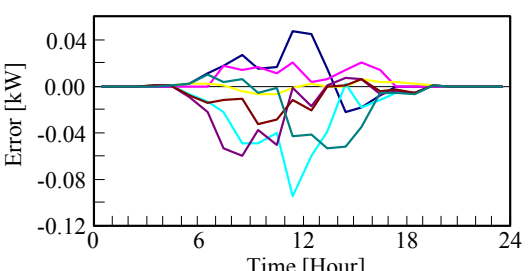

(b) August 1 to 7

Fig. 17 Error of power generation prediction of solar cell (S-3)

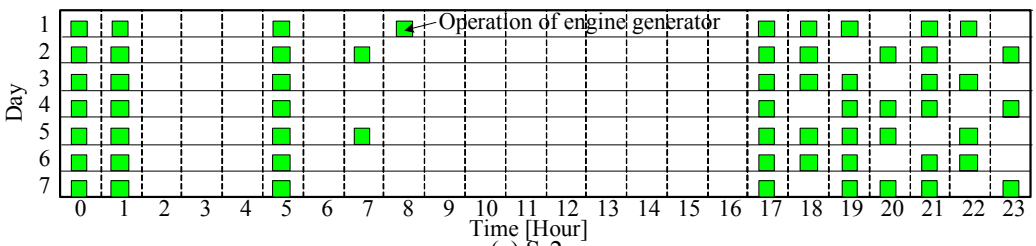

(a) S-2

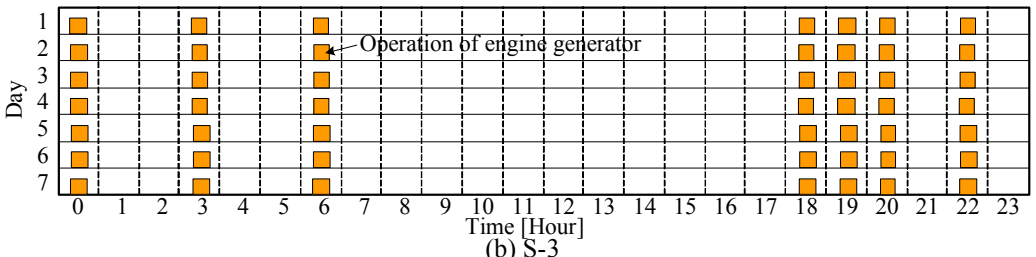

Fig. 18 Operating pattern of the engine generator in February

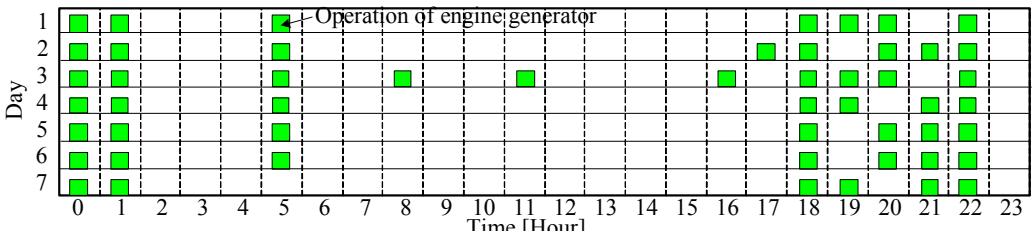

(a) S-2

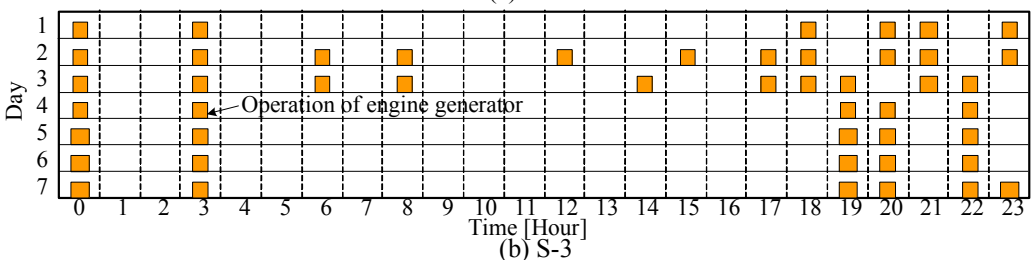

Fig. 19 Operating pattern of the engine generator in August

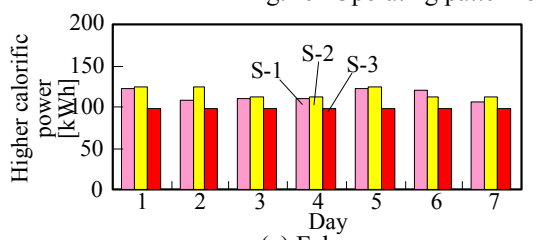

(a) February

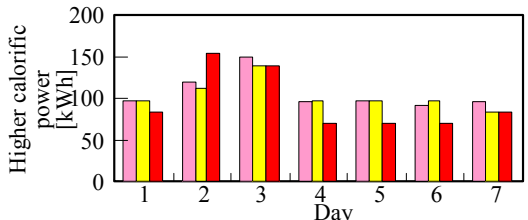

(b) August

Fig. 20 Fuel consumption in each system 
system is used is short in many respects. There is an excessive lack of solar radiation on August 2 and 3, hence the S-3 system operation for those days differs compared with the operation method of other days in the same week. However, the operation on August 3 in the S-2 system also differs from other days in the same week, although this is true to a lesser extent on August 2. The engine operation hours of the S-2 system on August 2 are 8 hours, as compared to 11 hours for the S-3 system. Moreover, despite the fact the engine operation hours of the S-2 system on August 3 total 10 hours, the operation hours of the S-3 system remain the same. The prediction errors of the electricity production of the solar cell of S-3 system on August 2 and 3 are 73\% and 37\%, respectively, as shown in Figs. 16 (b) and (c). When there is significant prediction error, the operation time of the engine generator of the S-3 system will become long. However, for example, although the prediction error in Fig. 15 (a) is $89 \%$, the operation hours of the engine generator on the same day shown in Fig. 18 (b) do not differ from other days in the same week. The fuel consumption of the S-3 system is more disadvantageous than that of the S-2 system, when the prediction error of the PAS is significant and the extreme lack of electricity production of the solar cell becomes a more frequent phenomenon. When the electricity production of the solar cell diminishes, the battery charge volume is insufficient. Moreover, when the prediction error of the PAS is considerable, the time shift of the power means a plan cannot be appropriately established, thus increasing the frequency of operation of the engine generator.

\subsection{Fuel consumption of each system}

Fig. 20 shows the result of the higher calorific power of the fuel consumed with the engine generator of each system. Except for August 2 and 3, the S-3 system shows little fuel consumption when clearly compared with other systems. However, it is difficult to compare the benefits of the S-1 and S-2 systems. When the fuel consumption of the S-1 system for the 1 st week in February is set to 1.0, the fuel consumption rates of the S-2 and S-3 systems are 1.02 and 0.85 , respectively. Moreover, when the fuel consumption of the S-1 system for the 1st week in August is set to 1.0, the fuel consumption rates of the S-2 and S-3 systems are 0.97 and 0.90 , respectively.

\section{Conclusions}

An algorithm to predict the production of electricity of the solar cell was developed, and operation plans in the case of its introduction into the hybrid system of a solar cell and a diesel engine generator were discussed. The following systems were examined in this paper: - An engine generator operated according to a load fluctuation system (S-1).

- When operating the engine, operate by a fixed load of maximum efficiency (3kW output power). If the battery capacity drops to $25 \%$ or less, the engine generator will be operated and the battery will be charged (S-2).

- Introduce the production-of-electricity prediction algorithm (PAS) of a solar cell, and determine the system operation method. Based on the predicted output characteristic of the solar cell, a plan is made for the operation or stop of the engine generator, and the operation of the charge or discharge process of the battery (S-3).

The operation of each system was analyzed using the meteorological data for the 1 st weeks in February and August, the differences in the operation results in each system were examined, and the following conclusions obtained.

(1) Estimation of relative merits is difficult for the fuel consumption of the S-1 and S-2 systems. Although we can state that the fuel consumption of the S-3 system is $10 \%$ to $15 \%$ lower when compared with other systems, there is significant prediction error of the electricity production of the solar cell, and when this latter declines, the fuel consumption of 
the S-3 system shows no superiority over other systems.

(2) The predictive accuracy of the PAS developed in this paper ranged from $4 \%$ to $89 \%$ in the 1st week in February and August. Even if the error of this range is added to the S-3 system, if the electricity production of the solar cell is that expected for an average year, there will be no significant difference in the operational planning within this system.

(3) The operation planning of the system with PAS is demonstrated as effective in terms of reducing the fuel consumption. Compared with the fuel consumption of the S-1 system in the 1st week in February, the S-2 and S-3 systems show a 2\% increase, and 15\% decrease, respectively. Moreover, compared with the S-1 system for the 1st week in August, they will record decreases of $3 \%$ and $10 \%$ respectively.

\section{References}

(1) M. Ashari and C. V. Nayar, An Optimum Dispatch Strategy Using Set Points for a Photovoltaic (PV)-Diesel-Battery Hybrid Power System, Solar Energy, 66(1), 1999, 1-9.

(2) M. Muselli, G. Notton and A. Louche, Design of Hybrid-Photovoltaic Power Generator, With Optimization of Energy Management, Solar Energy, 65(3), 1999, 143-157.

(3) Ismail Y, Kemmoku Y, Takikawa H and Sakakibara T, An Operating Method for Fuel Savings in a Stand-Alone Wind/Diesel/Battery System, Journal of Japan Solar Energy Society, 28(2), 2002, 31-38.

(4) Shigehiro Yamamoto, Kazuyoshi Sumi, Eiichi Nishikawa, Takeshi Hashimoto, An Operating Method Using Prediction of Photovoltaic Power for a Photovoltaic-Diesel Hybrid Power Generation System, Transactions of the Institute of Electrical Engineers of Japan, B, Power and Energy, 124(4), 2004, 521-530.

(5) NEDO Technical information data base, Standard meteorology and Solar radiation data (METPV-3), http://www.nedo.go.jp/database/index.html

(6) SANYO Nickel-Metal Hydride Production Information, (March 2007), Batterieshttp://www.sanyo.co.jp/energy/english/product/twicell_2.html

(7) Shin'ya Obara, Improvement of Power Generation Efficiency of an Independent Micro Grid Composed of Distributed Engine Generators, Transactions of the ASME, Journal of Energy Resources Technology, September 2007, Vol. 129, Issue 3, pp. 190-199.

(8) Shin'ya Obara, Energy Cost of an Independent Micro-grid with Control of Power Output Sharing of a Distributed Engine Generator, Journal of Thermal Science and Technology, Vol. 2, No. 1, (2007), pp.42-53.

(9) Narita, K., Research on Unused Energy of Cold Region Cities and Utilization for District Heat and Cooling, Ph.D. thesis, Hokkaido University. (1996).

(10) Takanobu Kosugi, Pyong Sik Pak and Yutaka Suzuki, Evaluation of Output and Unit Cost of Power Generation Systems Utilizing Solar Energy under Various Solar Radiation in the World, Transaction of the Institute of Electrical Engineers of Japan, Publication of Power and Energy Society, 118(3), 1998, 246-253.

(11) Solar Energy Utilization Handbook, Japan Solar Energy Society, 1985, 10-88, Ohmsha, Ltd. 